\title{
Alternatif Lokasi Terminal Sebagai Pusat Pertumbuhan Ekonomi di Doloksanggul Kabupaten Humbang Hasundutan
}

\author{
Jusmar Effendi Simamora ${ }^{1}$ \\ Dinas Tarukim, Kabupaten Humbang Hasundutan, Provinsi Sumatera Utara
}

\begin{abstract}
Asnawi
Jurusan Perencanaan Wilayah dan Kota, Fakultas Teknik

Universitas Diponegoro, Semarang
\end{abstract}

Artikel Masuk : 3 Juni 2014

Artikel Diterima : 13 Juli 2014

\begin{abstract}
Abstrak: Doloksanggul sebagai Ibukota Kabupaten Humbang Hasundutan sekaligus sebagai pusat pertumbuhan ekonomi hingga saat ini belum memiliki prasarana terminal. Akibatnya muncul terminal bayangan yang membuat kesemrawutan kota dan rendahnya kualitas jasa pelayanan angkutan umum, sehingga konektivitas antar dan intra pusat pertumbuhan ekonomi terganggu. Sementara terminal sebagai salah satu elemen transportasi darat dapat menimbulkan efek ekonomi berganda (multiplier effect) terhadap ekonomi lokal maupun regional, sehingga memiliki peran yang sangat strategis dalam mendukung pusat pertumbuhan ekonomi. Penelitian ini bertujuan untuk menentukan lokasi terminal yang mampu mendukung Doloksanggul sebagai pusat pertumbuhan ekonomi di Kabupaten Humbang Hasundutan melalui penilaian kriteria-kriteria yang dipakai. Untuk mencapai tujuan penelitian digunakan pendekatan kualitatif-deskriptif dan kuantitatif-deskriptif dengan menggunakan teknik purposive sampling, dengan membatasi responden hanya yang terkait langsung dengan permasalahan, yaitu pihak regulator, operator dan pengguna (penumpang). Metode analisis yang digunakan adalah metode Proses Hierarki Analitik (PHA), karena merupakan metode yang fleksibel dalam mengambil keputusan dengan mengkombinasikan berbagai pertimbangan untuk memperoleh pemecahan permasalahan multi kriteria. Kriteria yang dirumuskan adalah kemudahan aksesibilitas dari dan ke lokasi terminal, ketersediaan jaringan transportasi, tujuan akhir trayek angkutan umum AKAP/AKDP, berdekatan dengan pasar induk, terletak di pusat kota. Alternatif lokasi terminal terletak di Desa Bonanionan, Desa Pasaribu dan Desa Simangaronsang. Berdasarkan hasil analisis diperoleh bahwa lokasi terbaik adalah Desa Bonanionan dengan nilai 0,6022 (60,22\%) disusul Desa Pasaribu dengan nilai $0,3073(30,73 \%)$ dan yang terakhir adalah Desa Simangaronsang dengan nilai 0,0905 $(9,05 \%)$.
\end{abstract}

Kata kunci: alternatif lokasi, terminal, kriteria, metode PHA.

Abstract: Doloksanggul as the Capital District of Humbang Hasundutan also as the center economic growth until now has not had a terminal infrastructure. The result appears terminal shadows that make the city crowded and poor quality of public transport services, so that the

\footnotetext{
${ }^{1}$ Korespondensi Dinas Tarukim, Pemerintah Kabupaten Humbang Hasundutan, Provinsi Sumatera Utara Email: jusmar_pu@yahoo.com
} 


\section{Alternatif Lokasi Terminal sebagai Pusat Pertumbuhan Ekonomi di Doloksanggul...}

internal and external connectivity hub disrupted economic growth. While the terminal as one element of ground transportation can lead to multiple economic effects (multiplier effect) to the local and regional economy, so it has a very strategic role in supporting economic growth centers. This study aims to determine the location of the terminal is capable of supporting Doloksanggul as the center of economic growth in the District Humbang Hasundutan through assessment criteria used. To achieve the research objectives used a qualitative-descriptive and quantitative-descriptive approach which is using purposive sampling techniques, by restricting the respondent only directly related to the problem, namely regulators, operators and users (passengers). The analytical method used is the method of Analytic Hierarchy Process (AHP), because it is a flexible method of decision-making by combining a variety of considerations to obtain multi-criteria problem solving. The formulated criteria are the easies of accessibility to enter and from the terminal location, the availability of transportation networks, the ultimate destination of public transport track $A K A P / A K D P$, adjacent to the central market, located in the city center. The alternatives terminal location are located in the Bonanionan village, the Pasaribu village and the Simangaronsang village. Based on the results of the analysis found that the best location is the Bonanionan village with value of 0.6022 (60.22\%) followed the Pasaribu village with value of $0.3073(30.73 \%)$ and the last is the Simangaronsang village with value of 0.0905 (9.05\%).

Keywords: alternatives location, terminal, criteria, AHP method.

\section{Pendahuluan}

Doloksanggul sebagai Ibukota Kabupaten Humbang Hasundutan sampai saat ini belum memiliki prasarana terminal, sementara Doloksanggul sangat memungkinkan sebagai tempat transit (transitment point) bagi kegiatan ekonomi Provinsi Sumatera Utara di wilayah Tapanuli. Hal ini dikarenakan letak geografis Doloksanggul yang strategis, berada di pusat wilayah Tapanuli yang kelilingi oleh beberapa kabupaten dan satu kota, yaitu: Kabupaten Tapanuli Utara, Kabupaten Samosir, Kabupaten Toba Samosir, Kabupaten Dairi, Kabupaten Tapanuli Tengah, dan Kota Sibolga. Sebagai tempat transit, Doloksanggul harus memiliki prasarana terminal yang berfungsi sebagai titik simpul transportasi yang mampu mendukung pergerakan dan aktifitas masyarakat baik regional maupun lokal. Akibat ketiadaan prasarana terminal, konektivitas antar wilayah menjadi terganggu, yang berdampak negatif terhadap pertumbuhan ekonomi lokal maupun regional Kabupaten Humbang Hasundutan.

Sampai saat ini loket angkutan umum penumpang lokal maupun regional (AKAP/AKDP) yang beroperasi di Doloksanggul masih menggunakan badan jalan sebagai tempat parkir kendaraan dan aktifitas menaikkan dan menurunkan penumpang yang berfungsi sebagai terminal bayangan. Hal ini membuat kota semrawut dan tidak teratur sehingga penataan kota dan lalu lintas semakin sulit dilakukan. Bagi penumpang posisi terminal bayangan ini sangat merugikan karena rendahnya kualitas jasa pelayanan angkutan umum yang diterima penumpang akibat kurangnya kontrol dan monitoring dari pemerintah (regulator) terhadap pengusaha angkutan umum (operator) tentang pengaturan jadwal keberangkatan, tarif ongkos, kelaikan armada, rute trayek, dan lain-lain. Oleh karena itu perlu segera dilakukan upaya pembangunan terminal di Doloksanggul.

\section{Metode Penelitian}

Teknik pengumpulan data dalam penelitian ini digunakan dua cara, yaitu survei sekunder dan survei primer, yang bertujuan untuk mengumpulkan data primer dan 
sekunder. Teknik pengumpulan data primer dalam penelitian ini pada dasarnya merupakan perpaduan dua dasar, yaitu survei kuesioner (questionaire survey) dan survei wawancara (interview survey). Wawancara bermanfaat untuk menggali dan melengkapi data informasi tentang rumusan kriteria yang akan dipakai dalam mengidentifikasi lokasi alternatif terminal yang ada. Di samping itu tenaga survei juga melakukan survey lokasi yang berguna untuk mengetahui potensi (daya dukung area) lokasi terminal.

Teknik sampling yang dilakukan dalam penelitian ini adalah purposive sampling. Jumlah sampel yang diambil sebanyak 30 (tiga puluh) responden, terdiri dari pihak instansi Pemkab Humbang Hasundutan (regulator), pengusaha angkutan umum (operator), dan masyarakat sebagai penumpang yang secara proporsional masing-masing diwakili 10 (sepuluh) responden.

Untuk memilih lokasi lahan terminal yang terbaik dari beberapa alternatif lokasi digunakan metode Proses Hierarki Analitik (PHA). Metode analisis ini merupakan suatu model pendukung keputusan yang dikembangkan oleh Thomas L. Saaty. Model pendukung keputusan ini akan menguraikan masalah multi faktor atau multi kriteria yang kompleks menjadi suatu hierarki. Hierarki didefinisikan sebagai suatu representasi dari sebuah permasalahan yang kompleks dalam suatu struktur multi level, mulai dari tujuan, kriteria dan alternatif.

\section{Gambaran Umum}

Humbang Hasundutan adalah sebuah kabupaten di Sumatera Utara hasil pemekaran dari kabupaten induk Tapanuli Utara dengan ibukota Doloksanggul. Dibentuk pada 28 Juli 2003, dengan luas wilayah 2.517,66 km2, terdiri dari daratan $2.502,71 \mathrm{~km}^{2}$ dan danau $14,95 \mathrm{~km} 2$. Secara geografis Kabupaten Humbang Hasundutan terletak pada garis $2^{\circ} 1^{\prime}$ $2^{\circ} 28^{\prime}$ lintang utara dan $98^{\circ} 10^{\prime}-98^{\circ} 58^{\prime}$ bujur timur, dengan ketinggian antara $330-2.075 \mathrm{~m}$ di atas pemukaan laut. Secara administratif Kabupaten Humbang Hasundutan terdiri dari 10 (sepuluh) Kecamatan, yaitu Doloksanggul, Baktiraja, Lintong Nihuta, Onan Ganjang, Pakkat, Paranginan, Parlilitan, Pollung, Sijama Polang dan Tarabintang. Sejak tahun 2010, jumlah desa yang ada sebanyak 153 Desa dan 1 Kelurahan. Jumlah penduduk Kabupaten Humbang Hasundutan tahun 2011 berjumlah 173.255 jiwa yang terdiri dari 86.098 jiwa laki-laki dan 87.157 jiwa perempuan (Humbahas Dalam Angka, 2012). Jumlah penduduk Kecamatan Doloksanggul adalah 43.997 jiwa yang merupakan jumlah penduduk terbesar dari 9 kecamatan lainnya dan juga menjadi kecamatan terpadat dengan 206,39 jiwa per $\mathrm{km}^{2}$. Semboyan pemerintah Kabupaten Humbang Hasundutan adalah Huta Mas (Humbang Hasundutan Mandiri dan Sejahtera).

\section{Kajian Teori}

\section{Teori Terminal}

Dalam perencanaan terminal bus kriteria utama yang diterapkan (Santoso, 2007) adalah:

1. Terminal yang dimaksud hendaknya dapat mengantisipasi pergerakan pejalan kaki (pedesterian), yaitu mudah dicapai dari daerah sekitarnya.

2. Terminal yang dimaksud hendaknya dapat mengantisipasi sirkulasi pergerakan bus secara efektif dan efisien.

3. Terminal yang dimaksud hendaknya dapat mengantisipasi kebutuhan transfer secara cepat dan mudah. 


\section{Alternatif Lokasi Terminal sebagai Pusat Pertumbuhan Ekonomi di Doloksanggul...}

4. Terminal yang dimaksud hendaknya mampu mengantisipasi pergerakan kiss \& ride secara mudah dan cepat.

5. Terminal yang dimaksud hendaknya membuat penumpang merasa nyaman dan aman, baik untuk kegiatan naik bus, turun dari bus, maupun transfer antar lintasan bus.

6. Terminal yang dimaksud hendaknya adalah sedemikian sehingga bus dapat menaikturunkan penumpang secara mudah dan cepat.

7. Terminal yang dimaksud hendaknya sekecil mungkin mempengaruhi kondisi lalu lintas pada jaringan jalan di sekitarnya.

Menurut Iles (2005), perbedaan jenis layanan angkutan umum akan membedakan penentuan lokasi terminal, yaitu antara layanan bus perkotaan dan layanan jarak jauh. Hal ini dikarenakan perbedaan operator, perbedaan kelompok rute atau tujuan, atau karena perbedaan dari tipe kendaraan angkutan.

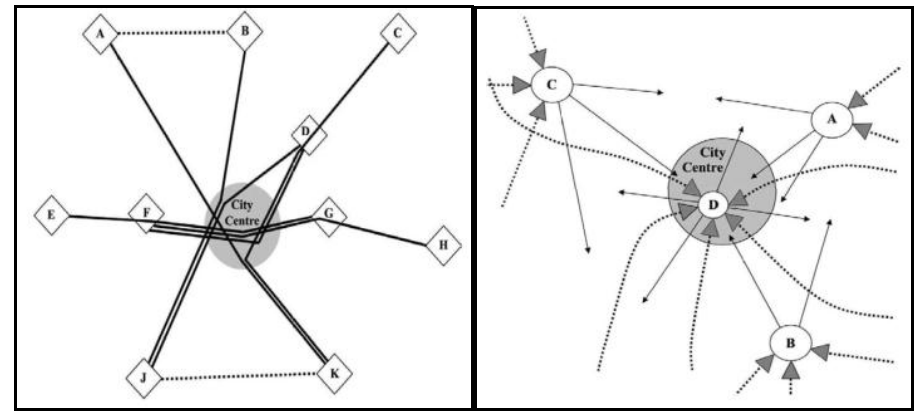

Sumber: Iles, 2005

\section{Gambar 1. Layanan Bus Perkotaan (Kiri); Layanan Jarak Jauh (Kanan)}

\section{Proses Hierarki Analitik (PHA)}

Proses Hierarki Analitik adalah suatu model yang luwes yang memberikan kesempatan bagi perorangan atau kelompok untuk membangun gagasan-gagasan dan mendefinisikan persoalan dengan cara membuat asumsi mereka masing-masing dan memperoleh pemecahan yang diinginkan darinya (Saaty, 1991).

\section{Pembandingan Berpasangan}

Menurut Saaty (1991), pembandingan berpasangan merupakan tahapan pertama dalam menetapkan prioritas elemen-elemen dalam suatu persoalan keputusan, yaitu dengan membandingkan elemen-elemen secara berpasangan terhadap suatu kriteria yang ditentukan. Untuk mengisi matriks banding berpasangan, digunakan bilangan untuk menggambarkan relatif pentingnya suatu elemen atas elemen lainnya, berkenaan dengan suatu sifat atau kriteria (seperti pada Tabel 1).

Tabel 1. Skala Banding Secara Berpasangan

\begin{tabular}{c|l|l}
\hline $\begin{array}{c}\text { Intensitas } \\
\text { Pentingnya }\end{array}$ & \multicolumn{1}{c|}{ Definisi } & \multicolumn{1}{c}{ Penjelasan } \\
\hline 1 & Kedua elemen sama pentingnya & $\begin{array}{l}\text { Dua elemen menyumbangnya sama besar } \\
\text { pada sifat itu }\end{array}$ \\
\hline 3 & Elemen yang satu sedikit lebih & Pengalaman dan pertimbangan sedikit \\
\hline
\end{tabular}




\begin{tabular}{|c|c|c|}
\hline $\begin{array}{l}\text { Intensitas } \\
\text { Pentingnya }\end{array}$ & Definisi & Penjelasan \\
\hline & penting ketimbang yang lainnya & menyokong satu elemen atas yang lainnya \\
\hline 5 & $\begin{array}{l}\text { Elemen yang satu esensial atau } \\
\text { sangat penting ketimbang elemen } \\
\text { lainnya }\end{array}$ & $\begin{array}{l}\text { Pengalaman dan pertimbangan dengan kuat } \\
\text { menyokong satu elemen atas elemen yang } \\
\text { lainnya }\end{array}$ \\
\hline 7 & $\begin{array}{l}\text { Satu elemen jelas lebih penting dari } \\
\text { elemen yang lainnya }\end{array}$ & $\begin{array}{l}\text { Satu elemen dengan kuat disokong, dan } \\
\text { dominannya telah terlihat dalam praktik }\end{array}$ \\
\hline 9 & $\begin{array}{l}\text { Satu elemen mutlak lebih penting } \\
\text { ketimbang elemen yang lainnya }\end{array}$ & $\begin{array}{l}\text { Bukti yang menyokong elemen yang satu atas } \\
\text { yang lain memiliki tingkat penegasan } \\
\text { tertinggi yang mungkin menguatkan }\end{array}$ \\
\hline $2,4,6,8$ & $\begin{array}{l}\text { Nilai-nilai antara di antara dua } \\
\text { pertimbangan yang berdekatan }\end{array}$ & $\begin{array}{l}\text { Kompromi diperlukan antara dua } \\
\text { pertimbangan }\end{array}$ \\
\hline Kebalikan & \multicolumn{2}{|c|}{$\begin{array}{l}\text { Jika untuk aktivitas } i \text { mendapat satu angka bila dibandingkan dengan aktivitas } j \text {, maka } j \\
\text { mempunyai nilai kebalikannya bila dibandingkan dengan } i \text {. }\end{array}$} \\
\hline
\end{tabular}

\section{Penilaian Perbandingan Multi Partisipan (Responden)}

Penilaian yang dilakukan oleh banyak partisipan (responden) akan menghasilkan pendapat yang berbeda satu sama lain. Metode PHA hanya membutuhkan satu jawaban untuk satu matriks perbandingan. Jadi semua jawaban dari partisipan (responden) harus dirata-ratakan. Untuk itu, Saaty (1991) menggunakan metode perataan Geometric Mean (GM). Secara matematis dapat ditulis sebagai berikut:

$$
g_{i j}=\left(z_{1} * z_{2} * \ldots * z_{n}\right)^{1 / n}
$$

\section{$\underline{\text { Konsistensi }}$}

Rasio konsistensi harus $\leq 10 \%$, jika tidak pertimbangan yang telah dibuat mungkin akan acak dan perlu diperbaiki. Indeks Konsistensi (Consistency Indeks, CI) adalah:

$$
C I=\frac{\lambda_{\operatorname{maks}}-n}{n-1}
$$

Selanjutnya batas ketidakkonsistensian yang ditetapkan Saaty, diukur dengan menggunakan Rasio Konsistensi (Consistency Ratio, CR), yakni perbandingan Indeks Konsistensi (CI) dengan nilai Indeks Random (RI) seperti Tabel 2. Perlu diperhatikan bahwa matrik berorde 1 dan 2 adalah konsitensi sehingga rumus CI/RI tidak berlaku.

$$
C R=\frac{C I}{R I}
$$

Tabel 2. Indeks Random untuk Orde Matriks

\begin{tabular}{c|c|c|c|c|c|c|c|c|c|c}
\hline $\mathrm{n}$ & 1 & 2 & 3 & 4 & 5 & 6 & 7 & 8 & 9 & 10 \\
\hline $\mathrm{RI}$ & 0 & 0 & 0,58 & 0,9 & 1,12 & 1,24 & 1,32 & 1,41 & 1,45 & 1,49 \\
\hline
\end{tabular}


Analisis

\section{Analisis Kriteria Pemilihan Lokasi Terminal}

Berdasarkan hasil survey peninjauan lokasi, pendapat dari stakeholder, studi literatur serta observasi ke terminal tipe A Kota Sibolga sebagai best practice yang hingga saat ini tetap eksis dan mampu mendukung kota Sibolga sebagai pusat pertumbuhan ekonomi, disimpulkan bahwa kriteria-kriteria yang menjadi pertimbangan dalam menentukan lokasi lahan terminal bus di Doloksanggul yang mampu mendukung pusat pertumbuhan ekonomi, yaitu:

\section{Kriteria 1: Kemudahan Aksesibilitas Dari dan Ke Lokasi Terminal}

Lokasi terminal yang mempunyai kemudahan aksesibilitas adalah lokasi terminal yang terletak dekat ke titik permintaan yang tinggi akan layanan transportasi sehingga akan memberikan kemudahan dan kenyamanan penumpang yang maksimum. Kemudahan ini dapat ditunjukkan dengan jarak tempuh, ongkos atau waktu tempuh dalam pencapaiannya, sehingga calon penumpang dapat dengan mudah mengakses lokasi tersebut bahkan dengan pergerakan pejalan kaki (pedesterian) untuk melakukan perjalanan yang mereka inginkan.

\section{Kriteria 2: Ketersediaan Jaringan Transportasi}

Diharapkan dengan ketersediaan jaringan transportasi sebagai suatu sistem transportasi yang baik, maka kemacetan di pusat kota yang disebabkan oleh bus yang beroperasi dan berakhir di sekitar terminal dapat diatasi. Hal ini bisa dilakukan dengan menghubungkan sebagian besar rute bus yang beroperasi di dalam kota dan yang menuju ke kota lain melalui pinggiran luar kota (ring road), sehingga berhenti di daerah pusat tidak lebih dari yang diperlukan untuk menurunkan dan menaikkan penumpang.

\section{Kriteria 3: Tujuan Akhir dari Trayek Angkutan Umum AKDP/AKAP}

Lokasi terminal yang akan dipilih akan mampu menjadi tujuan akhir dari rute bus untuk layanan jarak jauh dan menengah (AKAP/AKDP), karena lokasi terminal ini menjadi titik utama bangkitan dan pergerakan penumpang untuk angkutan jarak jauh dan menengah sehingga terminal akan melayani titik awal keberangkatan dan tujuan akhir perjalanan dari perjalanan rute jarak jauh dan menengah.

\section{Kriteria 4: Berdekatan Dengan Pasar Induk}

Pembangunan terminal pada kota kecil banyak yang tidak berfungsi secara maksimal bahkan ada yang tidak berfungsi sama sekali, beberapa indikator penyebab tidak berfungsinya terminal tersebut adalah karena letaknya yang berjauhan dari pasar. Sementara jika terminal yang dibangun berdekatan dengan pasar pada umumnya tetap eksis dan berfungsi dengan baik. Hal ini disebabkan karena keberadaan pasar dengan terminal mempunyai hubungan simbiosis mutualisma yang saling membutuhkan. Pasar mampumenciptakan permintaan (create demand) akan pelayanan jasa angkutan umum sedangkan terminal menyediakan (supply) jasa pelayanan angkutan umum.

\section{Kriteria 5: Terletak di Pusat Kota}

Jika hanya ada satu stasiun bus dengan pelayanan jarak jauh maka lokasi terminal harus ditempatkan di tempat yang sangat mudah untuk diakses dari semua bagian kota. Lokasi yang paling mudah untuk diakses dari semua bagian kota adalah di pusat kota, 
berada di jalur arteri primer yang melayani pergerakan penumpang untuk tujuan jarak jauh maupun lokal. Hal ini sesuai dengan prinsip lokasi terminal yang harus berlokasi dekat ke titik permintaan yang tinggi demi kenyamanan penumpang. Jika ada terminal bus di pusat kota, maka hal ini akan memberikan kenyamanan bagi penumpang untuk berganti moda angkutan (interchanging) antara rute.

\section{Analisis Matriks dan Bobot Kriteria Pemilihan Lokasi Terminal}

Hasil kuesioner tentang skala prioritas antar kriteria pemilihan lokasi terminal yang dapat mendukung Doloksanggul sebagai pusat pertumbuhan ekonomi setelah perataan Geometric Mean (GM) dari 30 (tiga puluh) responden, diperoleh nilai perbandingan antar kriteria seperti ditampilkan pada Tabel 3. Bahwa nilai skala perbandingan antara kriteria yang paling tinggi adalah kriteria 1 (kemudahan aksesibilitas dari dan ke lokasi terminal) dengan kriteria 2 (ketersediaan jaringan transportasi) yaitu 3,9731. Secara umum nilai skala perbandingan antara kriteria 4 (berdekatan dengan pasar induk) dengan kriteria lainnya menunjukkan angka yang lebih dominan. Hal ini menunjukkan bahwa sebagian besar persepsi responden menganggap bahwa sebuah terminal bus harus dekat dengan lokasi yang potensial bagi kebutuhan masyarakat, seperti pasar, perdagangan dan jasa.

Tabel 3. Nilai Perbandingan Antarkriteria

\begin{tabular}{c|c|c|c|c|c|c|c|c|c|c}
\hline \multirow{2}{*}{ Uraian } & \multicolumn{10}{c}{ Perbandingan antar kriteria } \\
\cline { 2 - 10 } & $\mathbf{1 : 2}$ & $\mathbf{1 : 3}$ & $\mathbf{1}: \mathbf{4}$ & $\mathbf{1}: \mathbf{5}$ & $\mathbf{2}: \mathbf{3}$ & $\mathbf{2}: \mathbf{4}$ & $\mathbf{2 : 5}$ & $\mathbf{3 : 4}$ & $\mathbf{3 : 5}$ & $\mathbf{4 : 5}$ \\
\hline Nilai perbandingan & 3,9731 & 1,5137 & 0,9802 & 0,8035 & 1,5641 & 0,7875 & 1,0137 & 0,6730 & 0,9209 & 1,4300 \\
\hline
\end{tabular}

Tabel 4. Matriks Painwise Comparison dan Local Priority Criteria

\begin{tabular}{c|c|c|c|c|c|c}
\hline Tujuan & $\mathbf{1}$ & $\mathbf{2}$ & $\mathbf{3}$ & $\mathbf{4}$ & $\mathbf{5}$ & Local Priority \\
\hline $\mathbf{1}$ & 1 & 3,9731 & 1,5137 & 0,9802 & 0,8035 & 0,2728 \\
\hline $\mathbf{2}$ & 0,2517 & 1 & 1,5641 & 0,7875 & 1,0137 & 0,1618 \\
\hline $\mathbf{3}$ & 0,6606 & 0,6393 & 1 & 0,6730 & 0,9209 & 0,1461 \\
\hline $\mathbf{4}$ & 1,0202 & 1,2698 & 1,4859 & 1 & 1,4300 & 0,2295 \\
\hline $\mathbf{5}$ & 1,2446 & 0,9865 & 1,0859 & 0,6993 & 1 & 0,1898 \\
\hline Jumlah & 4,1771 & 7,8687 & 6,6496 & 4,1400 & 5,1681 & \\
\hline
\end{tabular}

Pada Tabel 4 adalah bentuk matrik awal perbandingan antar kriteria, selanjutnya diperoleh perhitungan dari nilai eigen $(\lambda$ i), perhitungan vektor prioritas lokal (local priority). Dengan analisis menggunakan PHA, maka diperoleh hasil bahwa pada kolom vektor prioritas (local priority) terlihat bahwa Kriteria 1 (kemudahan aksesibilitas dari dan ke lokasi terminal) menjadi kriteria terpenting dari antara kriteria yang lainnya karena memiliki nilai yang paling besar yaitu 0,2728 (27,28\%), lalu diikuti oleh kriteria 4 (berdekatan dengan pusat pasar), kriteria 5 (terletak di pusat kota), kriteria 2 (ketersediaan jaringan transportasi) dan yang paling rendah kriteria 3 (tujuan akhir dari trayek angkutan umum AKAP/AKDP) yaitu 0,1461 (14,61\%). Hal ini menggambarkan bahwa persepsi responden menyatakan bahwa untuk penentuan lokasi lahan terminal maka kriteria terpentingnya adalah kemudahan aksesibilitas dari dan ke lokasi terminal. Kemudian dilakukan uji konsistensinya, dengan terlebih dahulu menghitung nilai eigen maksimum ( $\lambda$ maks) menggunakan rumus (2) dan indeks konsistensi (CI) menggunakan rumus (3) 


\section{Alternatif Lokasi Terminal sebagai Pusat Pertumbuhan Ekonomi di Doloksanggul...}

kemudian menghitung rasio konsistensi (CR) menggunakan rumus (4). Hasil perhitungan CI dan RI yang ditabulasikan adalah seperti pada Tabel 5 diperoleh nilai CR $=0,0641$, yang berarti nilai CR tersebut sudah sesuai dengan persyaratan konsistensi yaitu harus lebih kecil dari 0,1 atau lebih kecil dari 10\%. Apabila hasil perhitungan CR mendapatkan nilai lebih besar dari 0,1 atau lebih besar dari 10\% maka harus dipelajari kembali mengapa terjadi demikian, apakah terjadi kesalahan pengisian data atau memang persepsi responden yang tidak konsisten.

Tabel 5. Matriks Perhitungan Nilai Kriteria CR

\begin{tabular}{|c|c|c|c|c|c|c|c|}
\hline Tujuan & $\begin{array}{c}1 \\
(0,2728) \\
\end{array}$ & $\begin{array}{c}2 \\
(0,1618) \\
\end{array}$ & $\begin{array}{c}3 \\
(0,1461) \\
\end{array}$ & $\begin{array}{c}4 \\
(0,2295) \\
\end{array}$ & $\begin{array}{c}5 \\
(0,1898) \\
\end{array}$ & $\begin{array}{l}\text { Eigen } \\
\text { Vektor }\end{array}$ & $\begin{array}{c}\text { e-vektor } \\
\text { ll_priority }\end{array}$ \\
\hline 1 & 0,2728 & 0,6428 & 0,2212 & 0,2249 & 0,1525 & 1,5142 & 5,5498 \\
\hline 2 & 0,0687 & 0,1618 & 0,2285 & 0,1807 & 0,1924 & 0,8321 & 5,1434 \\
\hline 3 & 0,1802 & 0,1034 & 0,1461 & 0,1544 & 0,1748 & 0,7589 & 5,1944 \\
\hline 4 & 0,2784 & 0,2054 & 0,2171 & 0,2295 & 0,2714 & 1,2018 & 5,2375 \\
\hline 5 & 0,3396 & 0,1596 & 0,1586 & 0,1605 & 0,1898 & 1,0081 & 5,3108 \\
\hline \multicolumn{8}{|c|}{$\lambda m a k s=$ rata-rata pada (e-vektor $/ 1 \_$priority $)=5,2872$} \\
\hline \multicolumn{8}{|c|}{$\begin{aligned} C I & =\frac{\lambda_{m a k s}-n}{n-1} ; \mathrm{n}=5 \\
& =0,0718\end{aligned}$} \\
\hline \multicolumn{8}{|c|}{$\begin{aligned} C R & =\frac{C I}{R I} ; \mathrm{RI}=1,12(\text { Tabel } 2) \\
& =0,0641\end{aligned}$} \\
\hline
\end{tabular}

Sumber: Hasil analisis, 2013

\section{Analisis Alternatif Lokasi Terminal}

Berdasarkan sumber literatur (RTRW), pendapat dari stakeholder dan survey lokasi ke lapangan, maka ada 3 (tiga) lokasi alternatif lokasi terminal yang paling memungkinkan untuk diidentifikasi terhadap kriteria yang ada dalam penelitian ini, yaitu:

\section{Lokasi A: Desa Bonanionan}



Gambar 2. Lokasi Rencana Terminal Desa Bonanionan 
Lokasi ini terletak di ruas jalan Kolektor Primer (Jalan Nasional) Doloksanggul Sidikalang dengan kualitas jaringan jalan yang baik. Sesuai dengan RTRW Kabupaten Humbang Hasundutan, desa Bonanionan menjadi salah satu rencana lokasi terminal di Kabupaten Humbang Hasundutan. Luas lahan yang sudah dibebaskan Pemerintah Daerah \pm 3 ha. Ditinjau dari segi aksesibilitas dan jangkauan menuju ke lokasi ini termasuk relatif mudah dijangkau karena di samping berada di pusat kota dan dekat dengan pusat kegiatan masyarakat, seperti dengan pasar induk, pusat perdagangan dan jasa, dan pertokoan. Posisi lokasi desa Bonanionan yang berdekatan dan bersebelahan dengan pasar induk Doloksanggul diharapkan akan mendukung permintaan pergerakan dari dan ke lokasi pasar tersebut.

\section{Lokasi B: Desa Pasaribu}

Rencana lokasi terminal ini tepat berada di pusat kota, yang terletak di ruas jalan Doloksanggul - Siborongborong dengan status jalan Kolektor Primer (Jalan Nasional). Secara aksesibilitas lokasi ini sangat mudah dijangkau oleh masyarakat dari beberapa penjuru kota dengan berjalan kaki. Sedangkan untuk mencapai tujuan ke segala arah juga sangat mudah berganti moda angkutan karena letaknya tepat berada dipinggir jalan lalu lintas utama. Letaknya yang sangat strategis berada di pusat kota sangat cocok dijadikan menjadi tujuan akhir dari trayek angkutan umum AKAP/AKDP, sehingga akan memberikan kesempatan bagi angkutan lokal untuk berkembang dan berperan dalam pelayanan angkutan dalam kota. Relatif dekat dengan pasar induk Doloksanggul, hal ini akan sangat mendukung dan bersinergi akan pemenuhan permintaan pergerakan oleh pasar tersebut. Di atas lahan Lokasi alternatif desa Pasaribu ini telah terbangun gedung sekolah SMP, SD, dan kantor Polsek, yang hingga saat ini masih berfungsi dengan baik. Luas lahan keseluruhan adalah \pm 2 ha dan kemungkinan untuk perlusan sudah tidak memungkinkan.

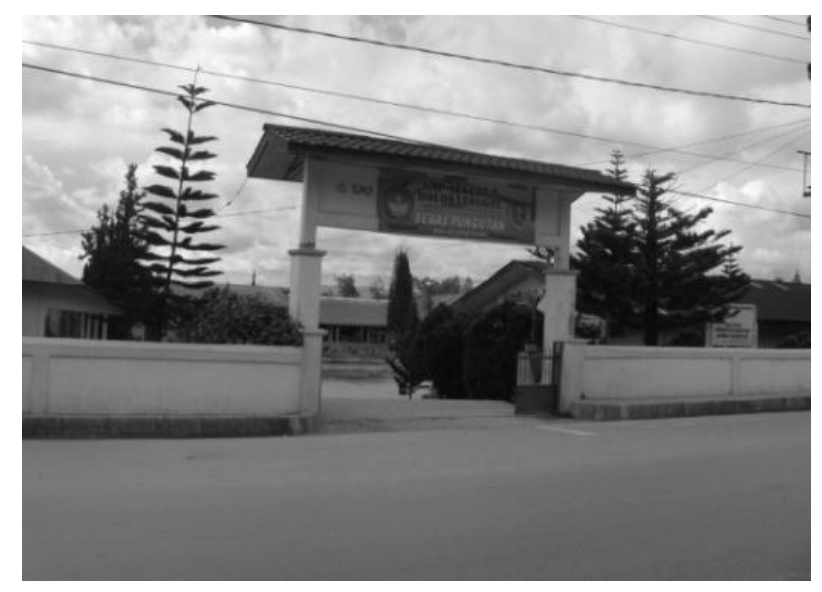

\section{Gambar 3. Lokasi Rencana Terminal Desa Pasaribu}

\section{Lokasi C: Desa Simangaronsang}

Lokasi ini merupakan lahan kosong tanah milik masyarakat yang terletak di ruas jalan Doloksanggul - Sidikalang dengan status jalan Kolektor Primer (Jalan Nasional), tetapi berada di pinggiran kota yang berdekatan dengan simpang jalan lingkar (ring-road). 


\section{Alternatif Lokasi Terminal sebagai Pusat Pertumbuhan Ekonomi di Doloksanggul...}

Aksesibilitas ke lokasi ini relatif sulit dijangkau karena jarak dari pusat kota $\pm 7 \mathrm{~km}$. Belum ada pusat kegiatan dan fasilitas umum yang terbangun di sekitar lokasi ini kecuali stadion sepakbola Simangaronsang, untuk saat ini kondisinya masih sangat sepi dan jauh dari pemukiman masyarakat dan fasilitas publik lainnya. Namun yang menjadi kelebihan lokasi ini adalah luas lahannya sangat tak terbatas, karena masih lahan kosong yang datar dan belum terbangun.

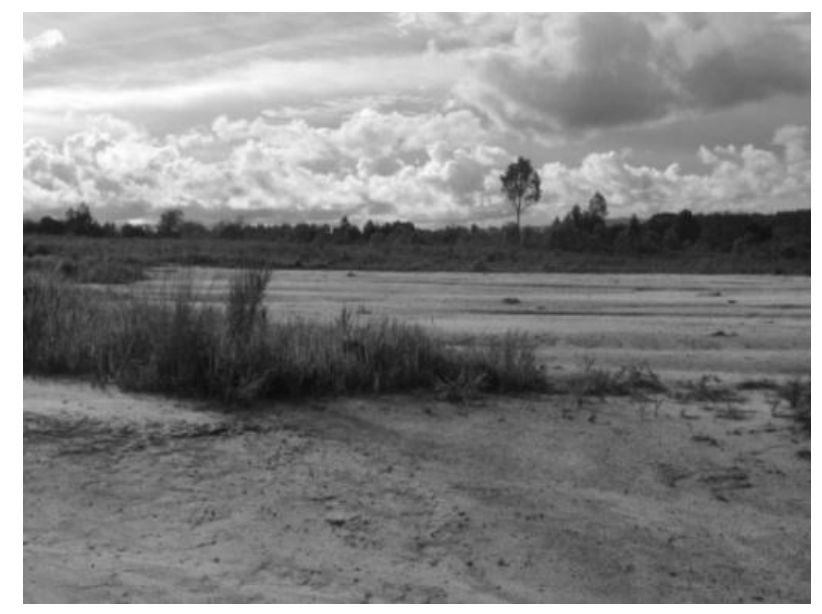

Gambar 4. Lokasi Rencana Terminal Desa Simangaronsang

\section{Analisis Matriks dan Bobot Alternatif Lokasi Terminal}

Berdasarkan hasil data yang didapatkan dari responden tentang skala prioritas antar kriteria pemilihan lokasi terminal dengan menggunakan metode perataan Geometric Mean (GM) dari 30 (tiga puluh) responden, diperoleh nilai perbandingan antar alternatif lokasi lahan berdasarkan kriteria seperti ditampilkan pada Tabel 6 .

Tabel 6. Nilai Perbandingan Antaralternatif Lokasi Terhadap Kriteria

\begin{tabular}{ll|c|c|c}
\hline \multirow{2}{*}{ Kriteria } & \multicolumn{2}{c}{ Nilai perbandingan antar alternatif lokasi } \\
\cline { 3 - 5 } & A : B & A : C & B : C \\
\hline 1. & Kemudahan aksebilitas dari dan ke lokasi terminal & 2,3663 & 5,5465 & 3,6440 \\
\hline 2. & Ketersediaan jaringan transportasi & 2,0776 & 5,4736 & 3,8431 \\
\hline 3. & $\begin{array}{l}\text { Tujuan akhir dari trayek angkutan umum } \\
\text { AKAP/AKDP }\end{array}$ & 2,5338 & 5,5301 & 3,6306 \\
\hline 4. & Berdekatan dengan pasar induk & 2,1953 & 7,2032 & 4,6385 \\
\hline 5. & Terletak di pusat kota & 2,1215 & 5,6785 & 3,7941 \\
\hline
\end{tabular}

Pada Tabel 6 berdasarkan kriteria 1 (kemudahan aksesibilitas dari dan ke lokasi terminal), nilai terbesar diperoleh pada perbandingan antara lokasi A (Desa Bonanionan) dengan lokasi C (Desa Simangaronsang) yaitu 5,5465. Kemudian diikuti oleh perbandingan antara lokasi B (Desa Pasaribu) dengan lokasi C (Desa Simangaronsang) yaitu 3,6440. Sedangkan nilai terendah diperoleh pada perbandingan antara lokasi A (Desa Bonanionan) dengan lokasi B (Desa Pasaribu) yaitu 2,3663. Ini menunjukkan bahwa berdasarkan kriteria kemudahan aksesibilitas dari dan ke lokasi terminal, persepsi responden menganggap sangat penting untuk memilih lokasi A daripada lokasi B atau lokasi C. 
Demikian pula selanjutnya secara keseluruhan nilai perbandingan antar alternatif lokasi terhadap semua kriteria yang ada menunjukkan bahwa persepsi responden mutlak menganggap untuk memilih lokasi A lebih penting daripada lokasi B atau lokasi C. Setelah melakukan identifikasi terhadap alternatif lokasi terminal berdasarkan kriteria untuk mendapatkan bobot dari masing-masing alternatif lokasi terhadap kriteria yang ada, maka langkah selanjutnya adalah melakukan perhitungkan perbandingan antar alternatif lokasi berdasarkan kriteria. Hasil perhitungan tersebut adalah:

a. Matriks pairwise comparison alternative lokasi berdasarkan kriteria kemudahan aksesibilitas dari dan ke lokasi terminal ditampilkan pada Tabel 7.

Tabel 7. Matriks Pairwise Comparison Alternatif Lokasi dan Local Priority Berdasarkan Kriteria 1

\begin{tabular}{c|c|c|c|c}
\hline $\begin{array}{c}\text { Kemudahan Aksesibilitas Dari dan ke } \\
\text { Lokasi Terminal }\end{array}$ & $\mathbf{A}$ & $\mathbf{B}$ & $\mathbf{C}$ & Local Priority \\
\hline $\mathbf{A}$ & 1 & 2,3663 & 5,5465 & 0,6061 \\
\hline $\mathbf{B}$ & 0,4226 & 1 & 3,6440 & 0,2986 \\
\hline $\mathbf{C}$ & 0,1803 & 0,2744 & 1 & 0,0953 \\
\hline Jumlah & 1,6029 & 3,6407 & 10,1905 & \\
\hline
\end{tabular}

Hasil perhitungan local priority terhadap alternatif lokasi kriteria 1 dapat dilihat bahwa persepsi responden terhadap lokasi A jika ditinjau dari kriteria kemudahan aksesibilitas dari dan ke lokasi terminal memperoleh nilai paling tinggi yaitu 0,6061 dan diikuti oleh lokasi B yaitu 0,2986 dan lokasi C yaitu 0,0953 atau dapat dikatakan bahwa responden lebih mengutamakan memilih lokasi A sebagai lokasi lahan terminal dari pada lokasi B dan C. Karena lokasi A berada dikawasan pusat Kota Doloksanggul yang mudah diakses dari semua bagian kota. Selanjutnya matrik ini juga akan diuji konsistensinya seperti ditampilkan pada Tabel 8 yang memperlihatkan nilai $C R=0,0186<0,1$ yang berarti nilai $C R$ tersebut sudah sesuai dengan persyaratan konsistensi harus lebih kecil dari 0,1 .

Tabel 8. Matriks Perhitungan CR Terhadap Alternatif Lokasi Berdasarkan Kriteria 1

\begin{tabular}{|c|c|c|c|c|c|}
\hline $\begin{array}{c}\text { Kemudahan Aksesibilitas Dari dan } \\
\text { ke Lokasi Terminal }\end{array}$ & $\begin{array}{c}\mathrm{A} \\
(0,6061) \\
\end{array}$ & $\begin{array}{c}\text { B } \\
(0,2986) \\
\end{array}$ & $\begin{array}{c}\mathrm{C} \\
(\mathbf{0 , 0 9 5 3 )} \\
\end{array}$ & $\begin{array}{l}\text { Eigen } \\
\text { Vektor }\end{array}$ & $\begin{array}{l}\text { e-vektor } \\
l \text { _priority }\end{array}$ \\
\hline A & 0,6061 & 0,7067 & 0,5288 & 1,8415 & 3,0384 \\
\hline $\mathrm{B}$ & 0,2561 & 0,2986 & 0,3474 & 0,9022 & 3,0209 \\
\hline $\mathrm{C}$ & 0,1093 & 0,0819 & 0,0953 & 0,2866 & 3,0058 \\
\hline \multicolumn{6}{|c|}{$\lambda m a k s=$ rata-rata pada (e-vektor /1_priority) $=3,0215$} \\
\hline \multicolumn{6}{|l|}{$\begin{aligned} C I & =\frac{\lambda_{m a k s}-n}{n-1} ; n=3 \\
& =0,0108\end{aligned}$} \\
\hline $\begin{aligned} C R & =\frac{C I}{R I} ; \mathrm{RI}=0,58(\text { Tabel } 2) \\
& =0,0186\end{aligned}$ & & & & & \\
\hline
\end{tabular}

b. Matrik pairwise comparison alternative lokasi berdasarkan kriteria ketersediaan jaringan transportasi ditampilkan pada Tabel 9.

Tabel 9. Matriks Pairwise Comparison Alternatif Lokasi dan Local Priority Berdasarkan Kriteria 2

\begin{tabular}{l|l|l|l|l}
\hline Ketersediaan Jaringan Transportasi & A & B & C & Local Priority \\
\hline
\end{tabular}


124 Alternatif Lokasi Terminal sebagai Pusat Pertumbuhan Ekonomi di Doloksanggul...

\begin{tabular}{c|l|l|l|l}
\hline A & 1 & 2,0776 & 5,4736 & 0,5847 \\
\hline B & 0,4813 & 1 & 3,8431 & 0,3204 \\
\hline C & 0,1827 & 0,2602 & 1 & 0,0949 \\
\hline Jumlah & 1,6640 & 3,3378 & 10,3167 & \\
\hline
\end{tabular}

Tabel 10. Matrik Perhitungan CR Terhadap Alternatif Lokasi Berdasarkan Kriteria 2

\begin{tabular}{|c|c|c|c|c|c|}
\hline $\begin{array}{c}\text { Ketersediaan Jaringan } \\
\text { Transportasi }\end{array}$ & $\begin{array}{c}\text { A } \\
(0,5847)\end{array}$ & $\begin{array}{c}\text { B } \\
(\mathbf{0 , 3 2 0 4 )}\end{array}$ & $\begin{array}{c}\mathrm{C} \\
(0,0949)\end{array}$ & $\begin{array}{l}\text { Eigen } \\
\text { Vektor }\end{array}$ & $\begin{array}{c}\text { e-vektor } \\
\text { l__priority }\end{array}$ \\
\hline $\mathbf{A}$ & 0,5847 & 0,6657 & 0,5194 & 1,7698 & 3,0270 \\
\hline B & 0,2814 & 0,3204 & 0,3647 & 0,9665 & 3,0162 \\
\hline C & 0,1068 & 0,0834 & 0,0949 & 0,2851 & 3,0042 \\
\hline \multicolumn{6}{|c|}{$\lambda m a k s=$ rata-rata pada (e-vektor $/ 1 \_$priority $)=3,0158$} \\
\hline \multicolumn{6}{|l|}{$\begin{aligned} C I & =\frac{\lambda_{\operatorname{maks}}-n}{n-1} ; \mathrm{n}=3 \\
& =0,0079\end{aligned}$} \\
\hline $\begin{aligned} C R & =\frac{C I}{R I} ; \mathrm{RI}=0,58(\text { Tabel } 2) \\
& =0,0136\end{aligned}$ & & & & & \\
\hline
\end{tabular}

Hasil perhitungan local priority terhadap alternatif lokasi kriteria 2 dapat dilihat bahwa persepsi responden terhadap lokasi A memperoleh nilai paling tinggi yaitu 0,5847 dan diikuti oleh lokasi B yaitu 0,3204 dan lokasi $C$ yaitu 0,0949 atau dapat dikatakan bahwa responden lebih mengutamakan memilih lokasi A sebagai lokasi lahan terminal dari pada lokasi B dan C. Karena lokasi A yang berada dikawasan pusat Kota Doloksanggul dianggap memiliki jaringan transportasi yang lebih baik. Selanjutnya matrik ini juga akan diuji konsistensinya seperti ditampilkan pada Tabel 10 yang memperlihatkan nilai $C R=0,0136<0,1$ yang berarti nilai $C R$ tersebut sudah sesuai dengan persyaratan konsistensi.

c. Matrik pairwise comparison alternative lokasi berdasarkan kriteria Tujuan akhir dari trayek angkutan umum AKDP/AKAP ditampilkan pada Tabel 14

Tabel 11. Matriks Pairwise Comparison Alternatif Lokasi dan Local Priority Berdasarkan Kriteria 3

\begin{tabular}{c|c|c|c|c}
\hline $\begin{array}{c}\text { Tujuan Akhir dari Trayek } \\
\text { Angkutan Umum AKAP/AKDP }\end{array}$ & A & B & C & $\begin{array}{c}\text { Local } \\
\text { Priority }\end{array}$ \\
\hline A & 1 & 2,5338 & 5,5301 & 0,6147 \\
\hline B & 0,3947 & 1 & 3,6306 & 0,2901 \\
\hline C & 0,1808 & 0,2754 & 1 & 0,0952 \\
\hline Jumlah & 1,5755 & 3,8092 & 10,1607 & \\
\hline
\end{tabular}

Tabel 12. Matriks Perhitungan CR Terhadap Alternatif Lokasi Berdasarkan Kriteria 3

\begin{tabular}{c|c|c|c|c|c}
\hline $\begin{array}{c}\text { Tujuan Akhir dari Trayek } \\
\text { Angkutan Umum AKAP/AKDP }\end{array}$ & $\begin{array}{c}\text { A } \\
(\mathbf{0 , 6 1 4 7 )}\end{array}$ & $\begin{array}{c}\text { B } \\
(\mathbf{0 , 2 9 0 1 )}\end{array}$ & $\begin{array}{c}\text { C } \\
(\mathbf{0 , 0 9 5 2 )}\end{array}$ & $\begin{array}{c}\text { Eigen } \\
\text { Vektor }\end{array}$ & $\begin{array}{c}\text { e-vektor } \\
\text { /_priority }\end{array}$ \\
\hline A & 0,6147 & 0,7351 & 0,5263 & 1,8761 & 3,0519 \\
\hline B & 0,2426 & 0,2901 & 0,3455 & 0,8782 & 3,0272 \\
\hline C & 0,1111 & 0,0799 & 0,0952 & 0,2862 & 3,0074 \\
\hline
\end{tabular}






Hasil perhitungan local priority terhadap alternatif lokasi kriteria 3 dapat dilihat bahwa persepsi responden terhadap lokasi A memperoleh nilai paling tinggi yaitu 0,6147 dan diikuti oleh lokasi B yaitu 0,2901 dan lokasi $C$ yaitu 0,0952 atau dapat dikatakan bahwa responden lebih mengutamakan memilih lokasi A sebagai lokasi lahan terminal dari pada lokasi B dan C. Karena lokasi A yang berada dikawasan pusat Kota Doloksanggul dianggap menjadi titik bangkitan dan pergerakan penumpang untuk rute jarak jauh dan menengah. Selanjutnya matrik ini juga akan diuji konsistensinya seperti ditampilkan pada Tabel 12 yang memperlihatkan nilai CR $=0,0248<0,1$ yang berarti nilai $C R$ tersebut sudah sesuai dengan persyaratan konsistensi harus lebih kecil dari 0,1 atau lebih kecil dari 10\%.

d. Matrik pairwise comparison alternative lokasi berdasarkan kriteria berdekatan dengan pasar induk ditampilkan pada Tabel 13. Hasil perhitungan local priority terhadap alternatif lokasi kriteria 4 dapat dilihat bahwa persepsi responden terhadap lokasi A memperoleh nilai paling tinggi yaitu 0,6106 dan diikuti oleh lokasi B yaitu 0,3134 dan lokasi $C$ yaitu 0,0761 atau dapat dikatakan bahwa responden lebih mengutamakan memilih lokasi A sebagai lokasi lahan terminal dari pada lokasi B dan C. Karena lokasi A yang berada sangat berdekatan dengan pasar induk Doloksanggul. Selanjutnya matrik ini juga akan diuji konsistensinya seperti ditampilkan pada Tabel 14 yang memperlihatkan nilai $\mathrm{CR}=0,0115<0,1$ yang berarti nilai $\mathrm{CR}$ tersebut sudah sesuai dengan persyaratan konsistensi.

\section{Tabel 13. Matriks Pairwise ComparisonAlternatif Lokasi dan Local Priority Berdasarkan Kriteria 4}

\begin{tabular}{c|c|c|c|c}
\hline Berdekatan dengan Pasar Induk & A & B & C & Local Priority \\
\hline A & 1 & 2,1953 & 7,2032 & 0,6106 \\
\hline B & 0,4555 & 1 & 4,6385 & 0,3134 \\
\hline C & 0,1388 & 0,2156 & 1 & 0,0761 \\
\hline Jumlah & 1,5943 & 3,4109 & 12,8417 & \\
\hline
\end{tabular}

Tabel 14. Matriks Perhitungan CR Terhadap Alternatif Lokasi Berdasarkan Kriteria 4

\begin{tabular}{|c|c|c|c|c|c|}
\hline Berdekatan dengan Pasar Induk & $\begin{array}{c}A \\
(0,6106) \\
\end{array}$ & $\begin{array}{c}\text { B } \\
(\mathbf{0 , 3 1 3 4}) \\
\end{array}$ & $\begin{array}{c}\mathrm{C} \\
(\mathbf{0 , 0 7 6 1 )}\end{array}$ & Eigen Vektor & e-vektor /l_priority \\
\hline $\mathbf{A}$ & 0,6106 & 0,6879 & 0,5479 & 1,8464 & 3,0241 \\
\hline B & 0,2781 & 0,3134 & 0,3528 & 0,9443 & 3,0134 \\
\hline C & 0,0847 & 0,0676 & 0,0761 & 0,2284 & 3,0026 \\
\hline \multicolumn{6}{|c|}{$\lambda m a k s=$ rata-rata pada (e-vektor /1_priority) $=3,0134$} \\
\hline \multicolumn{6}{|l|}{$\begin{aligned} C I & =\frac{\lambda_{\operatorname{maks}}-n}{\mathrm{n}-1} ; \mathrm{n}=3 \\
& =0,0067\end{aligned}$} \\
\hline $\begin{aligned} C R & =\frac{C I}{R I} ; \mathrm{RI}=0,58(\text { Tabel } 2) \\
& =0,0115\end{aligned}$ & & & & & \\
\hline
\end{tabular}


126 Alternatif Lokasi Terminal sebagai Pusat Pertumbuhan Ekonomi di Doloksanggul...

e. Matrik pairwise comparison alternative lokasi berdasarkan kriteria terletak di pusat kota ditampilkan pada Tabel 15.

Tabel 15. Matriks Pairwise Comparison Alternatif Lokasi dan Local Priority Berdasarkan Kriteria 5

\begin{tabular}{c|c|c|c|c}
\hline Terletak di Pusat Kota & A & B & C & Local Priority \\
\hline A & 1 & 2,1215 & 5,6785 & 0,5920 \\
\hline B & 0,4714 & 1 & 3,7941 & 0,3146 \\
\hline C & 0,1761 & 0,2636 & 1 & 0,0934 \\
\hline Jumlah & 1,6475 & 3,3851 & 10,4726 & \\
\hline
\end{tabular}

Tabel 16. Matriks Perhitungan CR Terhadap Alternatif Lokasi Berdasarkan Kriteria 5

\begin{tabular}{|c|c|c|c|c|c|}
\hline Terletak di Pusat Kota & $\begin{array}{c}\mathrm{A} \\
(0,5920)\end{array}$ & $\begin{array}{c}\text { B } \\
(\mathbf{0 , 3 1 4 6 )})\end{array}$ & $\begin{array}{c}\mathrm{C} \\
(\mathbf{0 , 0 9 3 4 )}\end{array}$ & Eigen Vektor & e-vektor /l_priority \\
\hline $\mathrm{A}$ & 0,5920 & 0,6674 & 0,5306 & 1,7900 & 3,0238 \\
\hline B & 0,2791 & 0,3146 & 0,3545 & 0,9482 & 3,0140 \\
\hline $\mathrm{C}$ & 0,1042 & 0,0829 & 0,0934 & 0,2805 & 3,0021 \\
\hline \multicolumn{6}{|c|}{$\lambda m a k s=$ rata-rata pada (e-vektor /1_priority) $=3,0133$} \\
\hline \multicolumn{6}{|l|}{$\begin{aligned} C I & =\frac{\lambda_{m a k s}-n}{n-1} ; n=3 \\
& =0,0066\end{aligned}$} \\
\hline \multicolumn{6}{|c|}{$\begin{aligned} C R & =\frac{C I}{R I} ; \mathrm{RI}=0,58(\text { Tabel } 2) \\
& =0,0115\end{aligned}$} \\
\hline
\end{tabular}

Hasil perhitungan local priority terhadap alternatif lokasi kriteria 5 dapat dilihat bahwa persepsi responden terhadap lokasi A memperoleh nilai paling tinggi yaitu 0,5920 dan diikuti oleh lokasi B yaitu 0,3146 dan lokasi $C$ yaitu 0,0934 atau dapat dikatakan bahwa responden lebih mengutamakan memilih lokasi A sebagai lokasi lahan terminal dari pada lokasi B dan C. Karena lokasi A yang berada dikawasan pusat Kota Doloksanggul sangat dekat dengan fasilitas pusat perdagangan, jasa, perkantoran, dan juga fasilitas lainnya. Selanjutnya matrik ini juga akan diuji konsistensinya seperti ditampilkan pada Tabel 16 yang memperlihatkan nilai $\mathrm{CR}=$ $0,0115<0,1$ yang berarti nilai CR tersebut sudah sesuai.

\section{Analisis Matriks Prioritas Global}

Setelah diperoleh nilai vektor prioritas (local priority) untuk matrik kriteria maupun untuk matrik alternatif lokasi, selanjutnya dilakukan penghitungan prioritas global. Nilai vektor prioritas pada matrik kriteria dan matrik alternatif lokasi berdasarkan kriteria, dimasukkan menjadi bobot pada matrik prioritas global seperti ditampilkan pada Tabel 17.

Tabel 17. Matriks Prioritas Global

\begin{tabular}{c|c|c|c|c|c|c}
\hline Kriteria/ & $\mathbf{1}$ & $\mathbf{2}$ & $\mathbf{3}$ & $\mathbf{4}$ & $\mathbf{5}$ & \multirow{2}{*}{ Global Priority } \\
\cline { 2 - 7 } Alternatif & 0,2728 & 0,1618 & 0,1461 & 0,2295 & 0,1898 & \\
\hline A & 0,6061 & 0,5847 & 0,6147 & 0,6106 & 0,5920 & 0,6022 \\
\hline B & 0,2986 & 0,3204 & 0,2901 & 0,3134 & 0,3146 & 0,3073 \\
\hline C & 0,0953 & 0,0949 & 0,0952 & 0,0761 & 0,0934 & 0,0905 \\
\hline
\end{tabular}


Dari tabel tersebut dapat dilihat bahwa lokasi A mendapat bobot tertinggi yaitu 0,6022 (60,22\%), kemudian lokasi B yaitu 0,3073 (30,73\%) dan yang terendah adalah lokasi C yaitu 0,0905 (9,05\%). Secara umum, persepsi responden lebih dominan memilih lokasi A (Desa Bonanionan) sebagai lokasi terbaik untuk lahan terminal bus di Doloksanggul.

Struktur hierarki dari kriteria dan alternatif lokasi dibuat menurut metode AHP seperti pada Gambar 5.

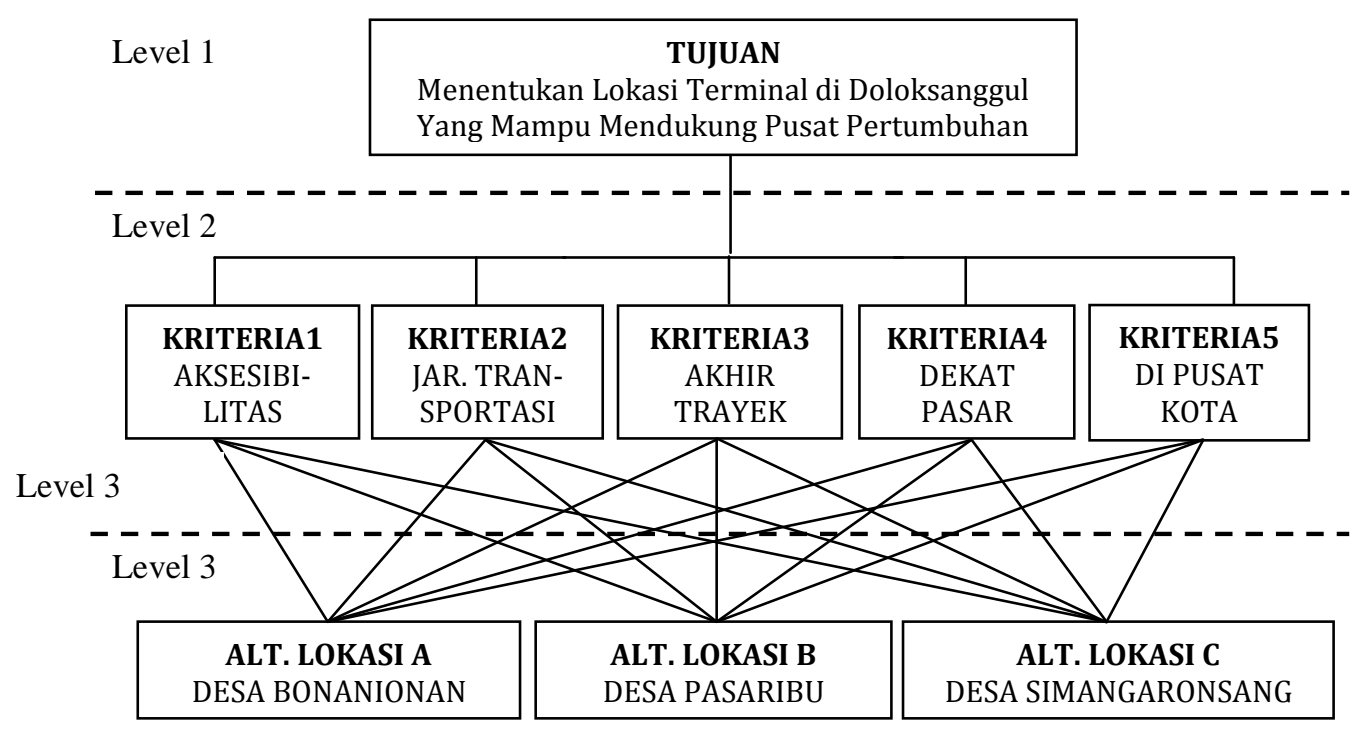

Gambar 5. Struktur Hierarki Model PHA

\section{Kesimpulan dan Rekomendasi}

\section{Kesimpulan}

Berdasarkan hasil analisis dan pembahasan, maka diambil beberapa kesimpulan sebagai berikut:

a. Hasil rumusan kriteria yang dilakukan dalam penelitian ini berdasarkan studi literatur, survey lokasi dan pendapat para stakeholder, maka yang menjadi pertimbangan dalam pemilihan lokasi terminal di Doloksanggul yang mampu mendukung pusat pertumbuhan ekonomi di Kabupaten Humbang Hasundutan adalah:

- Kriteria 1 : Kemudahan aksesibilitas dari dan ke lokasi terminal;

- Kriteria 2 : Ketersediaan jaringan transportasi;

- Kriteria 3 : Tujuan akhir dari trayek angkutan umum AKAP/AKDP;

- Kriteria 4 : Berdekatan dengan pasar induk;

- Kriteria 5 : Terletak di pusat kota.

b. Prioritas kriteria paling berpengaruh yang menjadi pertimbangan dalam pemilihan lokasi terminal di Dolok`sanggul Kabupaten Humbang Hasundutan adalah:

- Kemudahan aksesibilitas dari dan ke lokasi terminal (0,2666);

- Ketersediaan jaringan transportasi $(0,170)$;

- Tujuan akhir dari trayek angkutan umum AKAP/AKDP $(0,1708)$;

- Berdekatan dengan pusat pasar $(0,2218)$; 


\section{Alternatif Lokasi Terminal sebagai Pusat Pertumbuhan Ekonomi di Doloksanggul...}

- Terletak di pusat kota $(0,1543)$.

c. Hasil identifikasi terhadap ketiga alternatif loksai terminal berdasarkan masingmasing kriteria, maka yang menjadi lokasi terbaik adalah Lokasi A (Desa Bonanionan) dengan nilai 0,6022 (60,22\%), kemudian Lokasi B (Desa Pasaribu) dengan nilai 0,3073 (30,73\%)dan yang terakhir adalah Lokasi C (Desa Simangaronsang) dengan nilai 0,0905 (9,05\%).

\section{Rekomendasi}

Berdasarkan hasil analisis, pembahasan dan kesimpulan, maka direkomendasikan kepada Pemerintah Daerah Kabupaten Humbang Hasundutan sebagai berikut:

1. Merekomendasikan Lokasi Desa Bonanionan sebagai lokasi yang tepat untuk pemilihan lokasi pembangunan Terminal Tipe A di Doloksanggul Humbang Hasundutan.

2. Merekomendasikan pembangunan akses jalan baru yang menghubungkan jalan lingkar (ring-road) yang sudah ada dengan lokasi terminal Desa Bonanionan (ringroad by pass), untuk menghindari gangguan lalu lintas di pusat kota dimasa yang akan datang.

3. Merekomendasikan kajian menyeluruh perencanaan pembangunan drainase perkotaan sebelum melakukan pembangunan terminal di Desa Bonanionan.

\section{Daftar Pustaka}

Humbang Hasundutan dalam Angka 2012. Badan Pusat Statistik Kabupaten Humbang Hasundutan, 2012.

Iles, R. 2005. Public Transport In Developing Countries. Elsevier

Keputusan Menteri Perhubungan Nomor 31 Tahun 1995 tentang Terminal Transportasi Jalan

Rencana Tata Ruang Wilayah Kabupaten Humbang Hasundutan 2011-2031. Badan Perencanaan dan Pembangunan Daerah Kabupaten Humbang Hasundutan, 2012.

Saaty, T. L. 1988. Multicriteria Decision Making: The Analytical Hierarchy Process. Pittsburgh PA: RWS Publications.

Saaty, T.L. 1991. Pengambilan Keputusan: Bagi Para Pemimpin. Terjemahan Liana Setiono. Jakarta: Penerbit IPPM dan PBP.

Santoso, I. 1997. Perencanaan Sistem Angkutan Umum. Modul Pelatihan. Bandung: Jurusan Teknik Sipil, FTSP-ITB.

Satria, Budhi dkk. 2012. "Studi Alternatif Lokasi Lahan Terminal Bus Kota Sabang." Jurnal Teknik Sipil Pascasarjana Universitas Syiah Kuala, Vol. 1.1, Agustus. 